\title{
Mandioca minimamente processada submetida a radiação gama
}

\section{Fresh cut cassava subjected to gamma radiation}

\author{
Rogério Lopes Vieites ${ }^{1}$; Érica Regina Daiuto ${ }^{2 *}$; Lidia Raquel de Carvalho ${ }^{3}$; \\ Marcia Regina Garcia ${ }^{4}$; Mariana Gonçalves Lozano ${ }^{5}$; Ligia Mouriguchi Watanabe ${ }^{5}$
}

\section{Resumo}

\begin{abstract}
A mandioca minimamente processada é uma alternativa para prolongar o período de comercialização das raízes, agregando de valor a matéria prima e atendendo as necessidades do consumidor que procura produtos de fácil preparo. $\mathrm{O}$ objetivo desta pesquisa foi avaliar a qualidade de mandioca minimamente processada submetida radiação gama. No processamento mínimo foram utilizadas raízes de mandioca (IAC- 567-70) e, após o preparo foram acondicionadas em embalagens de poliestireno expandido e revestidas por filme plástico de polietileno de baixa densidade (PEBD) sendo irradiadas nas doses 0,0 (controle), 0,$5 ; 1,0 ; 1,5 ; 2,0 \mathrm{KGy}$. Foi obtido ainda outro tratamento cujas, raízes foram acondicionadas em embalagem de nylon+ polietileno com aplicação de vácuo. As raízes acondicionadas de todos os tratamentos foram armazenadas sob refrigeração $\left(5 \pm 1^{\circ} \mathrm{C}\right)$ e avaliações realizadas aos $0,3,6,9$ e 12 dias. As análises realizadas foram: acidez titulável, $\mathrm{pH}$, firmeza, coloração, atividade da enzima polifenoloxidase, tempo de cocção e porcentagem de hidratação das raízes. As avaliações seguiram apenas até o $9^{\circ}$ dia de armazenamento, pois após este período as raízes já apresentavam alterações fisiológicas e microbiológicas detectadas visualmente. Para acidez titulável, as raízes embaladas a vácuo obtiveram os menores valores, seguido do controle acondicionado em bandejas. Para os demais tratamentos observou-se aumento dos valores de acidez, tendo este comportamento influenciado nos valores de $\mathrm{pH}$. Para os demais parâmetros avaliados não ocorreu diferença significativa entre tratamentos, mas foram observadas alterações com o armazenamento. A firmeza diminuiu com o armazenamento. Os valores de luminosidade e componente de cor amarela diminuíram com o armazenamento e os valores de cor b* (verde) aumentaram. A atividade da enzima polifenoloxidase foi máxima no dia de elaboração do produto e diminuiu com o armazenamento. O tempo de cozimento e porcentagem de hidratação diminuíram com o armazenamento das raízes.
\end{abstract}

Palavras-chave: Manihot esculenta CRANTZ, polifenoloxidase, tempo de cocção, cor

\begin{abstract}
Fresh cut cassava is an alternative to prolong roots commercialization period, adding value to the raw material and assisting the consumer's needs that seeks for products of easy preparation. The aim of this work was to evaluate the quality of fresh cut cassava subjected to gamma radiation. For processing cassava roots (IAC - 567-70) were used, after preparation were packed in expanded polystyrene (EPS) trays, covered by low density polyethylene (LDPE) plastic film, being subjected to gamma radiation in the doses 0 (control), $0.5 ; 1.0 ; 1.5 ; 2.0 \mathrm{KGy}$. Another treatment was also carried out in which roots were vacuum packed in nylon + polyethylene. Packed roots of all treatments were stored under
\end{abstract}

\footnotetext{
${ }^{1}$ Prof. Dr. Dept ${ }^{\circ}$ de Gestão e Tecnologia de Alimentos. FCA/UNESP, Botucatu. E-mail: vieites@fca.unesp.br

${ }^{2}$ Pós doutoranda, programa CAPES/PNPD, no Dept ${ }^{\circ}$ de Horticultura da Faculdade de Ciências Agronômicas, UNESP, Botucatu. E-mail: erdaiuto@uol.com.br

${ }^{3}$ Prof $^{a}$ Dr $^{\mathrm{a}}$. do Dept ${ }^{\circ}$ de Bioestatística, Instituto de Biociências. UNESP, Botucatu. E-mail: lidiarc@ibb.unesp.br

${ }^{4}$ Nutricionista, Mestranda no curso Energia na Agricultura, FCA/UNESP, Botucatu. E-mail: garcia.marcinha@gmail.com

${ }^{5}$ Discente de graduação no curso de Nutrição, estagiária no Dept ${ }^{0}$ de Gestão e Tecnologia agroindustrial. Instituto de Biociências da UNESP, Botucatu. E-mail: chalaza.lozano@gmail.com; ligia.moriguchi@gmail.com

* Autor para correspondência
} 
refrigeration $\left(5 \pm 1{ }^{\circ} \mathrm{C}\right)$ and evaluations were made after $0,3,6,9$ and 12 days. Evaluated analyses were: titrable acidity, $\mathrm{pH}$, firmness, coloration, polyphenoloxidase activity, cooking time and roots hydration percentage. Evaluations just proceeded until the nine storage day, because after this period the roots already presented visually detectable physiologic and microbiological alterations. For titrable acidity, the vacuum packed roots had the lowest values, followed by the control packed in trays. For the other treatments, values of acidity increased and influenced the $\mathrm{pH}$ values. For the other appraised parameters there was no significant difference among treatments, but alterations were observed with the storage. The firmness decreased with the storage. Brightness values and yellow color component decreased with the storage and the $\mathrm{b} *$ (green) color values increased. Polyphenoloxidase activity was maximum in the day of elaboration of the product and it decreased with the storage. Cooking time and roots hydration percentage decreased with the roots storage.

Key words: Manihot esculenta CRANTZ, polyphenoloxidase, cooking time, color

\section{Introdução}

A conservação pós-colheita das raízes de mandioca é influenciada pela alta perecibilidade das raízes que possuem período curto de estocagem. A deterioração das raízes pode ser fisiológica, provocando a perda inicial da qualidade por meio do desenvolvimento da descoloração vascular do tecido parenquimatoso, ou, de ordem microbiana, que se segue à fisiologia, responsável pela decomposição do produto (ALVES et al., 2005; KATO; SOUZA, 1987).

Estes dois fenômenos afetam também as raízes descascadas e embaladas, a mandioca minimante processada (MMP).

A MMP é uma alternativa para promover a ampliação do período de oferta e disponibilizar um alimento mais prático, ou seja, descascado, limpo e higienizado, pronto para ser utilizado (OLIVEIRA; PANTAROTO; CEREDA, 2003).

Oprocessamento mínimo consiste na aplicação de operações tais como seleção, lavagem, sanitização, descascamento e corte, seguidos de centrifugação, embalagem e refrigeração, fornecendo alimentos de qualidade, conveniência e frescor (WILEY, 1994). Os cortes e danos mecânicos resultam em aumento das taxas de respiração e produção de etileno, com efeitos observados rapidamente, muitas vezes dentro de poucos minutos a poucas horas (MORETTI, 2007). Sabe-se também que vegetais minimamente processados podem conter microrganismos deteriorantes e bactérias patogênicas, representando um perigo potencial para a saúde (VESCOVO et al., 1996).

A eficiência do acondicionamento de raízes de mandioca em embalagens de polietileno com atmosfera controlada ou não, no monitoramento da deterioração fisiológica e manutenção da qualidade, constatando a preservação por diferentes períodos, dependendo do tipo de embalagem e aumentando a vida de útil deste produto, tem sido comprovada por alguns pesquisadores (ASSUNÇÃO et al., 2002; BEZERRA et al., 2002; CARVALHO; CHALFOUN; JUSTE JÚNIOR, 1985; GEORGE; BROWNE, 1994; GUIMARÃES et al., 2002; OUDIT, 1976; QUEVEDO; DATA; MATURAN, 1986; SILVA; SOARES; GERALDINI, 2003). Estas medidas associadas a refrigeração tem sido as alternativas propostas para conservação de MMP.

O uso de radiação gama é outro método físico que pode auxiliar na conservação de alimentos MMP. Segundo Wiley (1997), a ionização com radiações gama permite a desinfecção de produtos minimamente processados já embalados. A irradiação a doses baixas (1,0 kGy ou menor) tem sido sugerida como uma técnica de processamento mínimo para prolongar a vida útil de algumas frutas e hortaliças (KADER, 1986). Vegetais cortados e embalados, irradiados com doses na ordem de 1,0 kGy exibiram atraso de vários dias na sua decomposição quando armazenados a $10^{\circ} \mathrm{C}$ (URBAIN, 1986). Vieites, Evangelista e Silva (2000) trabalhando com melão minimamente processado e irradiado, verificaram que as doses 
de 0,1 e $0,2 \mathrm{kGy}$ apresentaram resultados positivos no controle do amadurecimento, na prevenção de doenças e na maior durabilidade do produto. Vieites et al. (2004) concluíram também que a irradiação nas doses de 0,4 e 0,5 kGy em diferentes embalagens foram efetivas no tratamento da manga Tommy Atkins minimamente processada.

A irradiação, utilizada isoladamente ou em conjunto com outras técnicas de preservação, como o processamento mínimo, pode facilitar o alcance dos objetivos de segurança de alimentos e redução de perdas pós-colheita (TAPE, 1996; SANTIN, 2000).

O objetivo desta pesquisa foi avaliar a qualidade de mandioca minimamente processada submetida a radiação gama.

\section{Materiais e Métodos}

Foi utilizada mandioca de mesa da variedade IAC-567-70. As raízes foram selecionadas, descartando-se aquelas que apresentavam injúrias. A seguir, foram lavadas em água corrente, descascadas manualmente, com posterior sanificação com solução de ácido cítrico $1 \%(\mathrm{~m} / \mathrm{v})$ por 20 minutos antes do acondicionamento. As pontas das raízes foram descartadas e a parte mediana foi cortada em cilindros de aproximadamente 8 $\mathrm{cm}$ de comprimento. As amostras, constituídas de quatro pedaços de raízes, foram acondicionadas em embalagens de poliestireno expandido $(0,25 \mathrm{x}$ $0,22 \mathrm{~m}$ ) e revestidas por filme plástico de polietileno de baixa densidade (PEBD) de 0,006 $\mathrm{mm}$ de espessura $\left(\mathrm{TPO}_{2} \mathrm{em} \mathrm{cm} \mathrm{cm}^{3} \cdot \mathrm{m}^{-2} \cdot \mathrm{dia}^{-1}\right.$ a $25^{\circ} \mathrm{C}$ e $1 \mathrm{~atm}$, de 18,1 e $\mathrm{TPCO}_{2}$ em $\mathrm{cm}^{3} \cdot \mathrm{m}^{-2} \cdot \mathrm{dia}^{-1}$ a $25^{\circ} \mathrm{C}$ e $1 \mathrm{~atm}$, de 75,6, área de permeabilidade de $790 \mathrm{~cm}^{2}$ ). Após acondicionamento as raízes minimamente processadas foram também submetidas a radiação gama (cobalto 60) nas doses de 0,0 (controle); 0,5; 1,$0 ; 1,5 ; 2,0 \mathrm{kGy}$, constituindo respectivamente, os tratamentos T1, T3, T4, T5 e T6. Foi obtido ainda outro tratamento cujas raízes foram acondicionadas em embalagem de nylon + polietileno com aplicação de vácuo (T2). As raízes acondicionadas de todos os tratamentos foram armazenadas sob refrigeração (5 $\pm 1{ }^{\circ} \mathrm{C}$ ) e avaliações foram realizadas aos $0,3,6$, 9 e 12 dias. Em cada tratamento foram feitas três repetições

\section{Análises físicas químicas}

Acidez total titulável (AT) e pH: realizada segundo a AOAC (1996) e acidez expressa em \% ácido cítrico, $\mathrm{m} \mathrm{m}$ - de acordo com o Instituto Adolfo Lutz (2008). Foram realizadas três leituras em cada uma das três repetições em todos os tratamentos.

Cor: A cor foi medida em colorímetro da marca Konica Minolta (Chroma meter, CR 400/410) e expressa pelo sistema de coordenadas retangulares $\mathrm{L} \mathrm{a}^{*} \mathrm{~b}$ * conforme a CIE (Comission Internatinale d'Eclairage), onde $\mathrm{L}^{*}$ expressa em porcentagem valores de luminosidade $(0 \%=$ negro e $100 \%=$ branco), a* representa as cores vermelha $(+)$ ou verde (-) e $b^{*}$ as cores amarela $(+)$ ou azul (-). Foram realizadas três leituras em cada uma das três repetições em todos os tratamentos, em diferentes pontos das raízes..

Firmeza: utilizando-se um texturômetro (STEVENS - LFRA texture analyser) com a distância de penetração de $20 \mathrm{~mm}$, velocidade de $2,0 \mathrm{~mm} \mathrm{~s}^{-1}$ e ponta de prova TA 9/1000, os resultados foram apresentados em gramas força por centímetro quadrado $\left(\mathrm{gf} / \mathrm{cm}^{2}\right)$. Foram realizadas cinco leituras em cada uma das três repetições em todos os tratamentos.

\section{Avaliação da atividade enzimática}

\section{Atividade Polifenoloxidase (PPO, EC. 1.14.18.1)}

A extração e determinação da enzima foram realizadas de acordo com método de Cano et al. (1997), com adaptações para mandioca, ajustandose o pH da solução tampão para 7,0. A análise foi realizada em triplicata e os resultados expressões em 
$\mathrm{UAE} / \mathrm{min} / \mathrm{g}$ de matéria fresca. Por favor, detalhar mais para que possa haver dados para reprodução da técnica para essa matéria-prima.

Avaliação de parâmetros de qualidade culinária das raizes

Tempo de cozimento: avaliado segundo procedimento realizado por Bezerra et al. (2002), usando-se $50 \mathrm{~g}$ de raízes em pedaços imersos em $1000 \mathrm{~mL}$ de água em ebulição, até que o material não apresentasse resistência à perfuração por garfo de aço inoxidável.

Porcentagem de hidratação das raízes: obtida pela diferença de peso das raízes frescas e após a cocção e resfriamento da amostra, calculada em porcentagem de ganho de peso em relação ao peso inicial, sem considerar os sólidos e os solúveis perdidos na água de cocção.

As determinações relacionadas aos parâmetros de qualidade foram realizadas em triplicata.

A deterioração fisiológica foi avaliada pelo acompanhamento visual das raízes armazenadas, mediante observação do início do estriamento vascular.

Foi realizada a análise de variância para comparação de médias utilizando o teste de Tukey a $5 \%$ de probabilidade Os dados foram também submetidos a análise de regressão para avaliar o comportamento das variáveis em função do tempo de armazenamento. A análise estatística foi realizada usando o software SAS 9.2.

\section{Resultados e Discussões}

Análises físico-quimicas

Acidez total titulável e $\mathrm{pH}$

Observou-se diferença nas MMP entre os tratamentos e a média geral mostra que as MMP dos tratamentos T3, T4 e T5 foram aqueles que alcançaram maiores valores de AT ao longo do armazenamento, 1,78; 1,58 e 2,03 ( \% ácido cítrico, $\mathrm{m} \mathrm{m}^{-}$), respectivamente. $\mathrm{O}$ T2, que correspondente às raízes embaladas a vácuo foi o que alcançou menor valor de AT (1,28\% \% ácido cítrico, $\left.\mathrm{m} \mathrm{m}^{-}\right)$, seguido das raízes do tratamento testemunha e dose

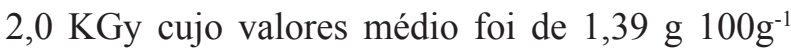
de raiz. Exceto para T2, as MMP demonstraram um aumento dos valores de AT como observado na Figura 1. A acidez final do T2 foi de 1,20\% ácido citrico, $\mathrm{m} \mathrm{m}$.

O comportamento obtido para AT refletiu nos resultados obtidos para o $\mathrm{pH}$ (Figura 2). Para os valores de $\mathrm{pH}$ houve diferença entre os tratamentos, e de modo geral os valores foram menores quando a acidez foi maior. Bezerra et al. (2002) também obtiveram aumento do AT com o período de armazenamento para MMP. Estes autores realizaram a avaliação de MMP submetidas ao branqueamento, acondicionadas em embalagens de polietileno de 100 micrômetros de espessura, fechadas com arames plastificados. Alves et al. (2005) obtiveram em MMP, valores de uma acidez média para os tratamentos "bandeja", "selado" e "vácuo", de 5,34\%, 4,33\% e $2,40 \%$, respectivamente, sem encontrar diferença durante os dias de armazenamento. Estes autores encontraram ligeiro aumento nos teores de acidez nas raízes do tratamento selado até o $7^{\circ}$ dia e do tratamento a vácuo até o $14^{\circ}$ dia de armazenamento. Segundo Bezerra et al. (2002) o aumento da AT pode ser devido ao início de um processo fermentativo bacteriano com o consumo do oxigênio e produção de ácidos orgânicos, como o lático, butírico, acético, entre outros. Já a redução do pH está relacionada com o aumento da AT. 
Figura 1. Conteúdo de acidez total titulável (\% ácido cítrico, $\mathrm{m} \mathrm{m}$ ) para MMP submetidas a radiação a radiação gama (ajustes referentes aos tratamentos).

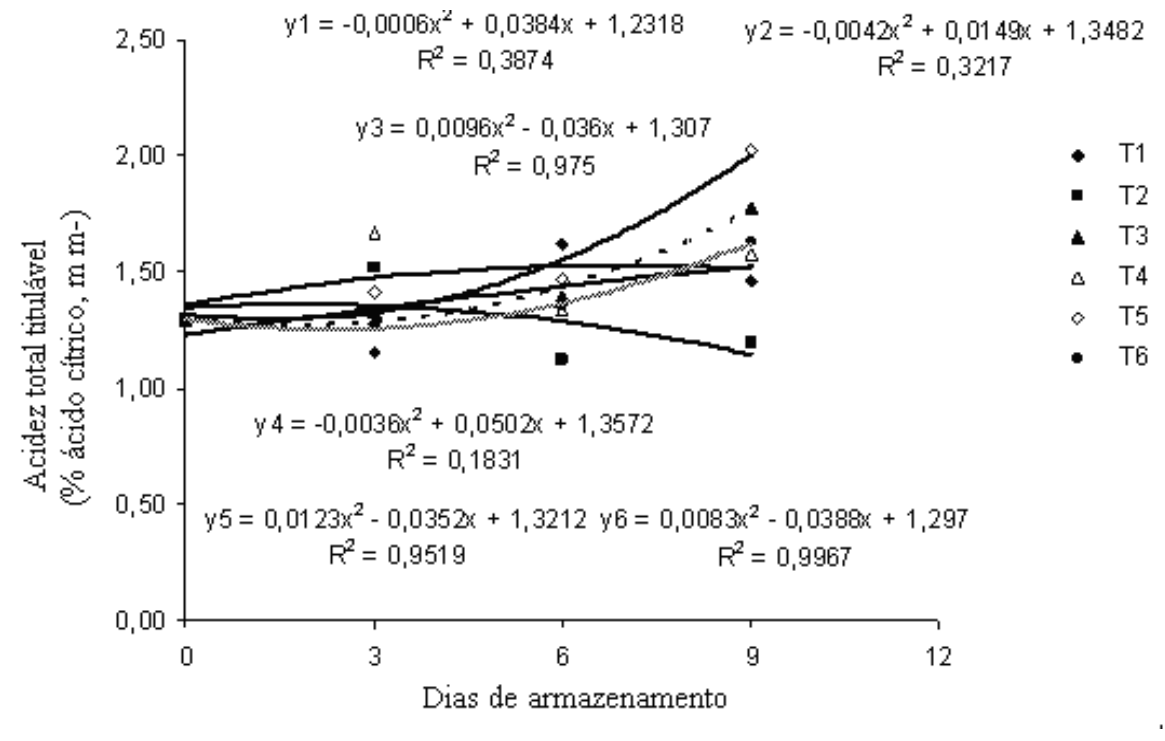

Legenda: $\mathrm{T} 1=$ controle, $\mathrm{T} 2=$ controle com vácuo, T3=0,5 KGy, T4=1,0 KGy, T5 = 1,5 KGy e T6=2,0 KGy.

Figura 2. Valores de pH para MMP submetidas a radiação gama (ajustes referentes aos tratamentos).

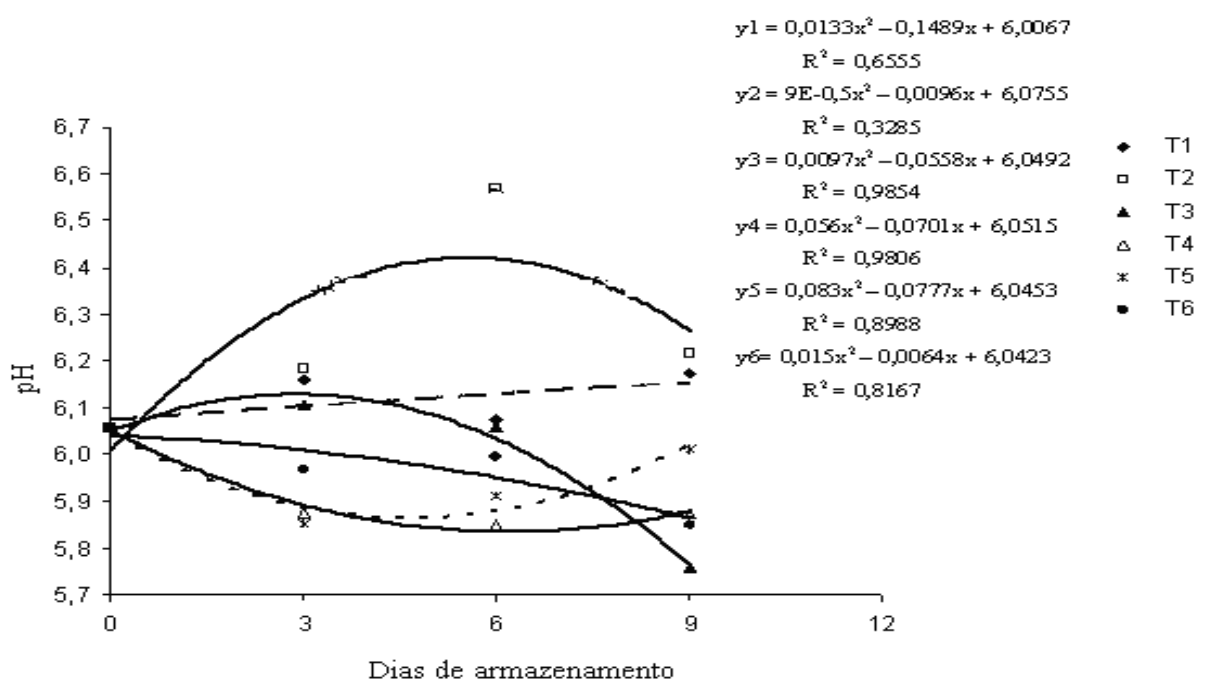

Legenda: $\mathrm{T} 1=$ controle, $\mathrm{T} 2=$ controle com vácuo, T3=0,5 KGy, T4=1,0 KGy, T5 = 1,5 KGy e T6=2,0 KGy.

\section{Firmeza}

Em relação à firmeza das MMP (Tabela 1), não foi observada diferença estatística significativa nas MMP entre tratamentos, sendo os valores médios obtidos entre 1006,0 a 1009,7 (gf/ $\left.\mathrm{cm}^{2}\right)$. Foi possível o ajuste de uma equação para os tratamentos segundo os dias de armazenamento.
Observou-se um aumento discreto dos valores de firmeza entre o 3 e o $6^{\circ}$ dias de armazenamento seguido de diminuição. Este aumento dos valores de firmeza pode ter ocorrido devido a perda de massa das MMP, pois o corte e descasque expõe os tecidos internos hidratados e aumenta drasticamente a taxa de evaporação da água (BURTON, 1982). 
Outra explicação para este aumento dos valores de firmeza seria a lignificação dos tecidos, pois o corte e o descasque podem provocar a ativação de mecanismos de defesa culminando na deposição de lignina e suberina nas paredes das células injuriadas (DIXON; PAIVA, 1995; DYER et al., 1989), possivelmente seguido da subdivisão celular sob o tecido suberizado para a recomposição da periderme (BURTON, 1982). PINELI (2005) atribui também à desidratação e a deposição de lignina e suberina como os fatores responsáveis pelo aumento de firmeza e outras alterações superficiais observadas em batatas minimamente processadas embaladas na ausência de vácuo.

Tabela 1. Firmeza $\left(\mathrm{gf} / \mathrm{cm}^{2}\right)$ em MMP submetidas a radiação gama.

\begin{tabular}{lccccc}
\hline \multicolumn{7}{c}{ Dias de armazenamento } \\
\hline Tratamento & $\mathbf{0}$ & $\mathbf{3}$ & $\mathbf{6}$ & $\mathbf{9}$ & $\begin{array}{c}\text { Média geral de } \\
\text { tratamento }\end{array}$ \\
\hline $\mathrm{T} 1$ & $1006,7 \pm 4,9$ & $1010,7 \pm 1,5$ & $1010,7 \pm 45,0$ & $1010,7 \pm 5,0$ & $1009,7 \pm 4,0$ \\
T2 & $1006,7 \pm 4,9$ & $1011,7 \pm 2,3$ & $1006,3 \pm 16,5$ & $1010,7 \pm 5,9$ & $1008,8 \pm 8,2$ \\
T3 & $1006,7 \pm 4,9$ & $1018,7 \pm 3,8$ & $1000,3 \pm 10,3$ & $1009,7 \pm 5,1$ & $1008,8 \pm 8,9$ \\
T4 & $1006,7 \pm 4,9$ & $1007,0 \pm 5,3$ & $1007,0 \pm 2,0$ & $1011,0 \pm 9,2$ & $1007,9 \pm 5,4$ \\
T5 & $1006,7 \pm 4,9$ & $1010,7 \pm 7,0$ & $1005,7 \pm 7,2$ & $1001,0 \pm 2,0$ & $1006,0 \pm 6,0$ \\
T6 & $1006,7 \pm 4,9$ & $1016,0 \pm 2,6$ & $1004,7 \pm 4,2$ & $1007,0 \pm 1,7$ & $1008,6 \pm 5,5$ \\
\hline Média geral de dia & $1006,7 \mathrm{~b} \pm 4,1$ & $1012,4 \mathrm{a} \pm 5,3$ & $1005,8 \mathrm{~b} \pm 8,1$ & $1008,3 \mathrm{ab} \pm 5,8$ & \\
\hline
\end{tabular}

Houve efeito de dia $(\mathrm{p}=0,01) \quad$ Letras minúsculas comparam médias gerais de dia

Legenda: $\mathrm{T} 1=$ controle, $\mathrm{T} 2=$ controle com vácuo, $\mathrm{T} 3=0,5 \mathrm{KGy}, \mathrm{T} 4=1,0 \mathrm{KGy}, \mathrm{T} 5=1,5 \mathrm{KGy}$ e T6=2,0 KGy.

\section{Coloração}

Para os valores de luminosidade, cor a* e cor b* não ocorreu diferença estatística significativa entre as raízes de mandioca dos tratamentos. A faixa de valores médios dos tratamentos para de luminosidade, $\mathrm{a}^{*} \mathrm{e} \mathrm{b}^{*}$ foram, respectivamente, de 90,1 a $90,8 \%,-1,70$ a 1,621 a e 11,6 a 12,4 (média geral dos tratamentos)

Já para os dias de armazenamento a tendência obtida pode ser observada nas Figuras (3,4 e 5). Ocorreu diminuição dos valores de luminosidade, que foi mais expressiva após o $6^{\circ}$ dia de armazenamento. $\mathrm{O}$ parâmetro de cor $\mathrm{a}^{*}$ negativa indica a presença do componente de cor verde nas MMP, e durante o armazenamento ocorreu diminuição dos valores negativos da intensidade deste componente de cor. Os valores do parâmetro de cor b positivo indicam a presença de componente de cor amarelo, que aumentaram ao longo do período de armazenamento, após o $3^{\circ}$ dia.

Costa Neto, Spoto e Domarco (1997), estudando a irradiação de mandiocas de mesa "in natura" (variedade IAC - 59/210, branca), observaram que no segundo dia do experimento, a testemunha apresentou valor $\mathrm{L}$ mais baixo se comparada a amostras tratadas com irradiação, indicando que não apresentaram tais alterações, exceto leve tonalidade amarelada, que decresceu em função do aumento da dose aplicada. A amostra irradiada com $10 \mathrm{kGy}$ apresentou cor idêntica ao controle fresco. Estes autores testaram doses de 2 a $10 \mathrm{kGy}$ e verificaram que a irradiação com doses de 8 a 10 kGy inibe o escurecimento da MMP em embalagens de polietileno, mantendo suas características físicas e sensoriais durante nove dias de armazenamento. Pedroso (2005) encontrou valores de luminosidade inferiores para a amostra controle das MMP em embalagem de polietileno a vácuo, que foram armazenadas até 21 dias sob refrigeração. A variedade utilizada pelo autor foi a mesma utilizada nesta pesquisa. Para os autores as amostras de MMP submetidas a doses de irradiação de 1,2 e 3 kGy, mantiveram valores de Lentre 86,63, 85,69 e 84,68 $\%$ até os 30 dias de armazenamento. 
Figura 3. Luminosidade (\%) para MMP submetidas a radiação gama (média geral dos dias ).

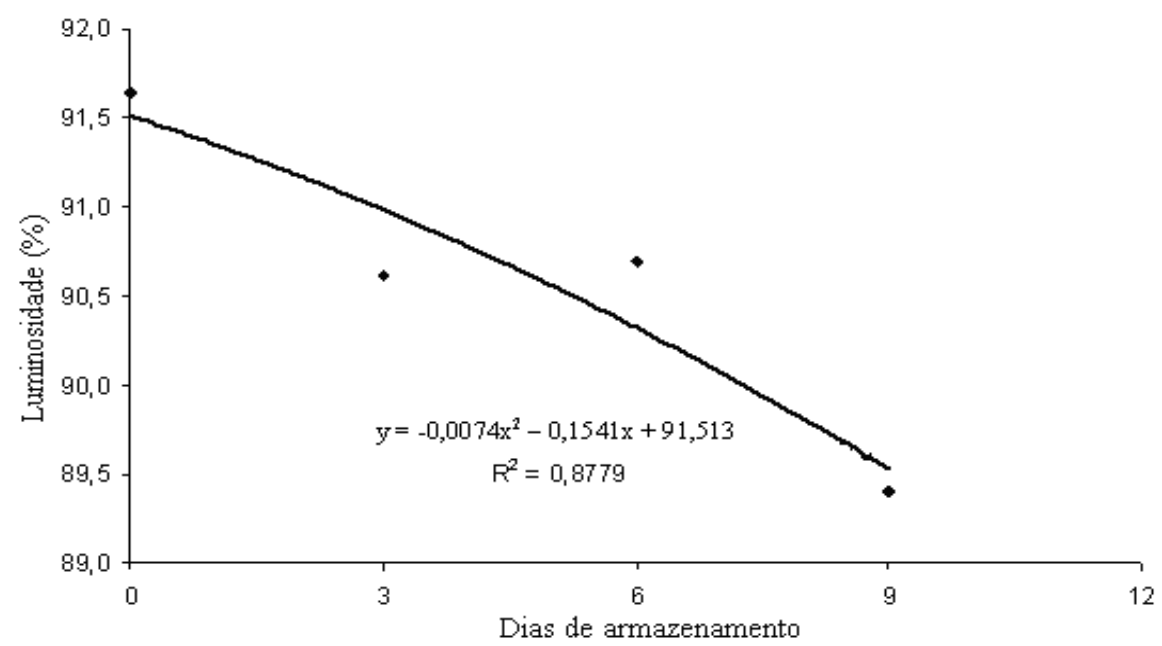

Figura 4. Cor a* para MMP submetida a radiação gama (média geral dos dias).

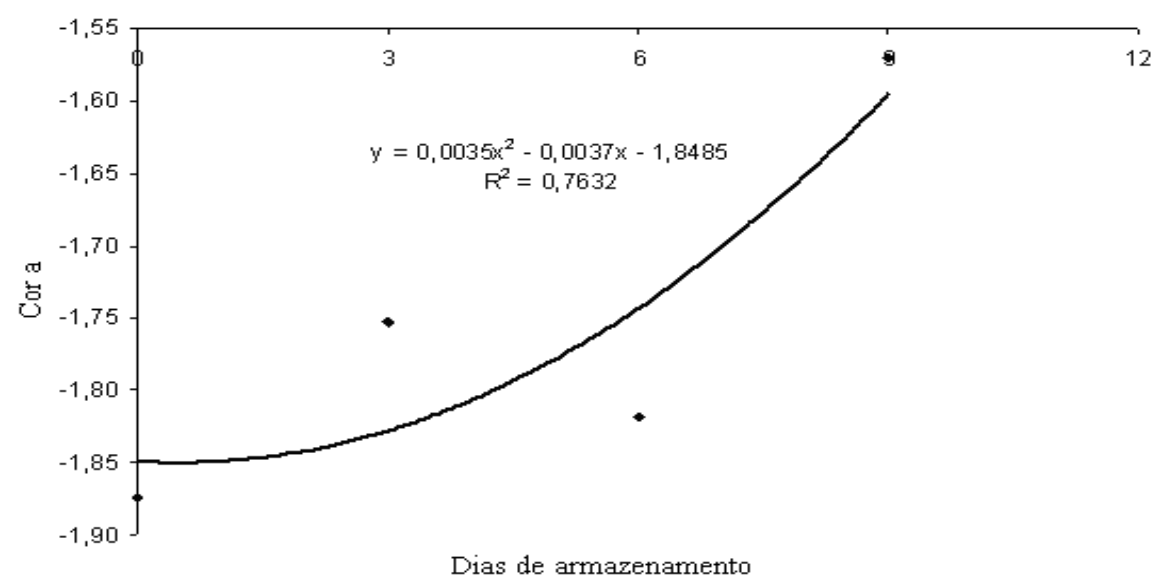

Figura 5. Cor $b^{*}$ para MMP submetida a radiação gama (média geral dos dias).

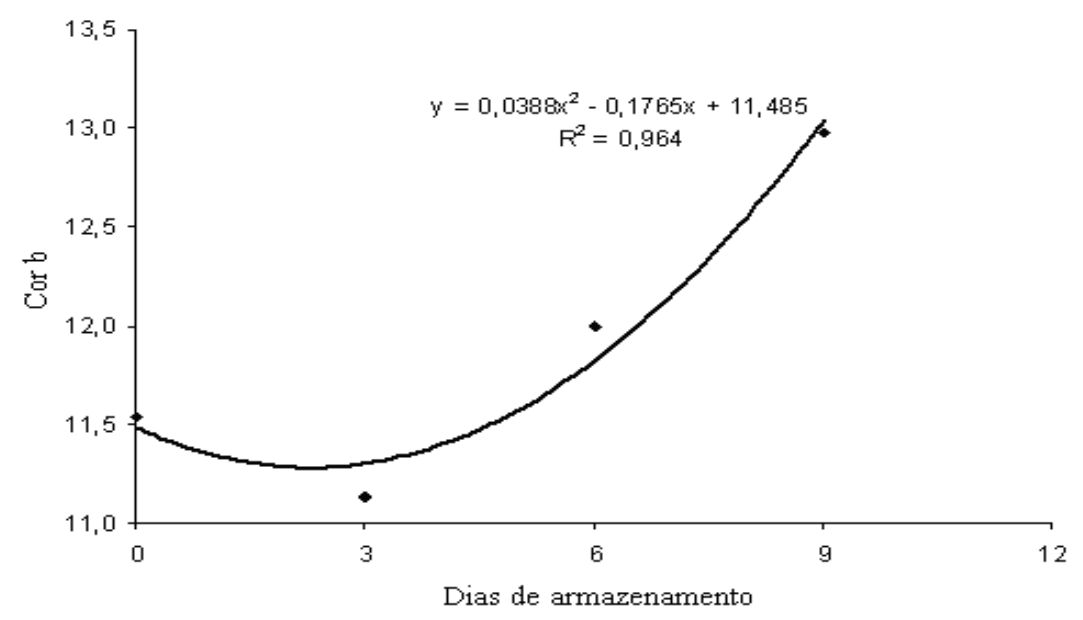

Semina: Ciências Agrárias, Londrina, v. 33, n. 1, p. 271-282, jan./mar. 2012 
Atividade da enzima polifenoloxidase

A deterioração fisiológica, que ocorre logo após a colheita, durante a qual a raiz desenvolve estrias azuladas (MONTALDO, 1973), tem sido estreitamente relacionada com mudanças oxidativas das substâncias fenólicas e com as enzimas envolvidas na oxidação desses compostos, como a peroxidase e a polifenoloxidase (CARVALHO; CHALFOUN; JUSTE JÚNIOR, 1985).

Os valores da PPO nas raízes variaram de 135,0 a 145,2 U.g ${ }^{-1} \cdot$ minuto $^{-1}$ para os tratamentos (média

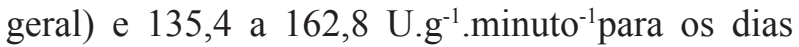
(média geral). Não foi observada diferença entre as MMP dos tratamentos, sendo possível obter uma equação de regressão única. Pôde-se observar diminuição da atividade da PPO após o $3^{\circ}$ dia de armazenamento (Tabela 2). $\mathrm{O}$ armazenamento refrigerado pode ter auxiliado na redução da atividade desta enzima. Segundo Abreu, Santos e Costa (1998), as variações na atividade da PPO em hortaliças são decorrentes das espécies, condições de cultivo e manejo. Por exemplo, em maçãs, há decréscimo da atividade da PPO com aumento da maturação (COSETENG; LEE, 1987), enquanto que para pêssegos (BASSI; SELLI, 1990), assim como observado nas MMP, o comportamento foi contrário.

Bezerra et al. (2002) encontraram valores da atividade de 34,73 a $91,98 \mathrm{U}^{-1} \mathrm{~g}^{-1} \cdot$ minuto $^{-1}$ durante o período de armazenamento, e raízes sem branqueamento apresentaram atividade máxima no $11^{\circ}$ dia de armazenamento; as raízes branqueadas, por sua vez, aos 18 dias de armazenamento. A partir destes momentos também houve decréscimo na atividade da enzima, conforme constatado nesta pesquisa. Esses valores assemelham-se aos encontrados por Coelho (1992) ao avaliar diferentes idades de colheita de três cultivares de mandioca,

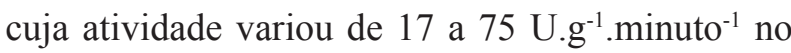
dia da colheita.

Não foi observada nesta pesquisa relação entre a alteração da cor das raízes e a atividade da enzima. Pineli (2005) também não encontrou relação entre esta enzima e escurecimento em batatas minimamente processadas.

Tabela 2. Atividade da PPO $\left(\mathrm{U} \cdot \mathrm{g}^{-1} \cdot \mathrm{minuto}^{-1}\right)$ em MMP.

\begin{tabular}{lcllll}
\hline \multicolumn{7}{c}{ Dias de armazenamento } \\
\hline Tratamento & \multicolumn{1}{c}{$\mathbf{0}$} & \multicolumn{1}{c}{$\mathbf{3}$} & \multicolumn{1}{c}{$\mathbf{6}$} & \multicolumn{1}{c}{$\mathbf{9}$} & $\begin{array}{c}\text { Média geral de } \\
\text { tratamento }\end{array}$ \\
\hline T1 & $162,8 \pm 46,7$ & $146,1 \pm 14,0$ & $119,1 \pm 9,0$ & $152,8 \pm 7,1$ & $145,2 \pm 27,2$ \\
T2 & $162,8 \pm 46,7$ & $162,6 \pm 8,0$ & $136,1 \pm 12,5$ & $124,3 \pm 16,0$ & $146,4 \pm 28,1$ \\
T3 & $162,8 \pm 46,7$ & $178,1 \pm 1,6$ & $69,3 \pm 11,9$ & $147,0 \pm 9,5$ & $139,3 \pm 48,5$ \\
T4 & $162,8 \pm 46,7$ & $172,6 \pm 10,3$ & $130,9 \pm 35,0$ & $134,6 \pm 14,8$ & $150,2 \pm 32,0$ \\
T5 & $162,8 \pm 46,7$ & $192,2 \pm 16,2$ & $122,4 \pm 12,1$ & $128,5 \pm 15,8$ & $151,5 \pm 37,1$ \\
T6 & $162,8 \pm 46,7$ & $147,2 \pm 14,2$ & $105,2 \pm 11,9$ & $125,0 \pm 6,4$ & $135,0 \pm 31,4$ \\
\hline Média geral de dia & $162,8 \mathrm{a} \pm 39,2$ & $166,5 \mathrm{a} \pm 19,7$ & $113,8 \mathrm{~b} \pm 27,3$ & $135,4 \mathrm{~b} \pm 15,3$ & \\
\hline
\end{tabular}

Houve efeito de dia $(\mathrm{p}=0,002)$. Letras minúsculas comparam médias gerais de dia Legenda: T1= controle, T2= controle com vácuo, T3=0,5 KGy, T4=1,0 KGy, T5 = 1,5 KGy e T6=2,0 KGy.

\section{Parâmetros de qualidade}

Não houve diferença significativa para os tratamentos em relação ao tempo de cozimento das MMP. A média geral dos dias para o T1, T2, T3, T4, T5 e T6 foram, respectivamente, de 15,5; 14,7; 15,$7 ; 14,9 ; 16,8$ e 18,2 .
Na Figura 6 observa-se diminuição do tempo de cozimento ao longo do período de armazenamento.

Segundo Pereira, Lorenzi e Valle (1985) 11 a 20 min é um tempo considerado adequado para este parâmetro avaliado. Cereda et al. (1990) relataram 13,5 min como tempo de cozimento para a cultivar 
IAPAR-19 Pioneira colhida aos 12 meses. Bezerra et al. (2002) observaram diferenças significativas do tempo de cocção das raízes em função dos períodos de armazenamento, mesmo com reduzida amplitude de valores, variando de 24,85 a 27,70 minutos e aumentando com o armazenamento.

\section{Porcentagem de hidratação}

Também não foi observada diferença estatística significativa entre os tratamentos, mas ao longo dos dias de armazenamento ocorreu redução da porcentagem de hidratação das MMP (Figura 7). A porcentagem de hidratação variou de 12,5 para o tratamento controle a 19,8 \% no tratamento com dose de 1,5 KGy (média geral dos tratamentos). Apesar de não ser observada diferença significativa entre tratamentos, observa-se um aumento da porcentagem de hidratação com o aumento da dose de radiação gama.

Figura 6. Tempo de cocção (minutos) em MMP submetida a radiação gama (média geral dos dias de armazenamento).

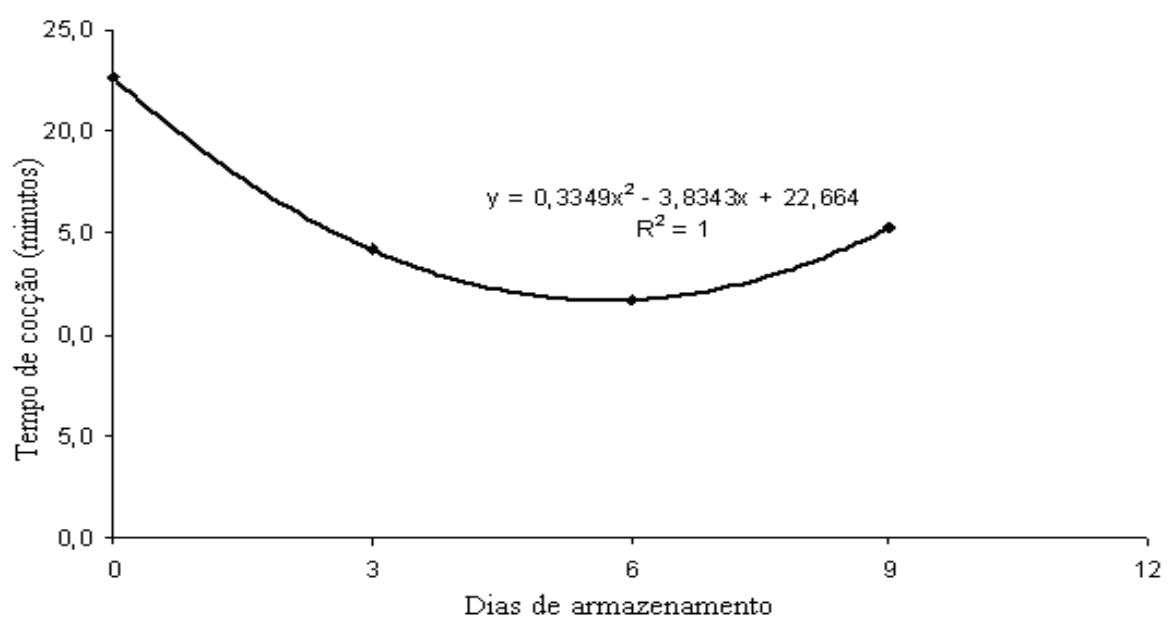

Figura 7. Porcentagem de hidratação (\%) em MMP submetida a radiação gama (média geral dos dias de armazenamento).

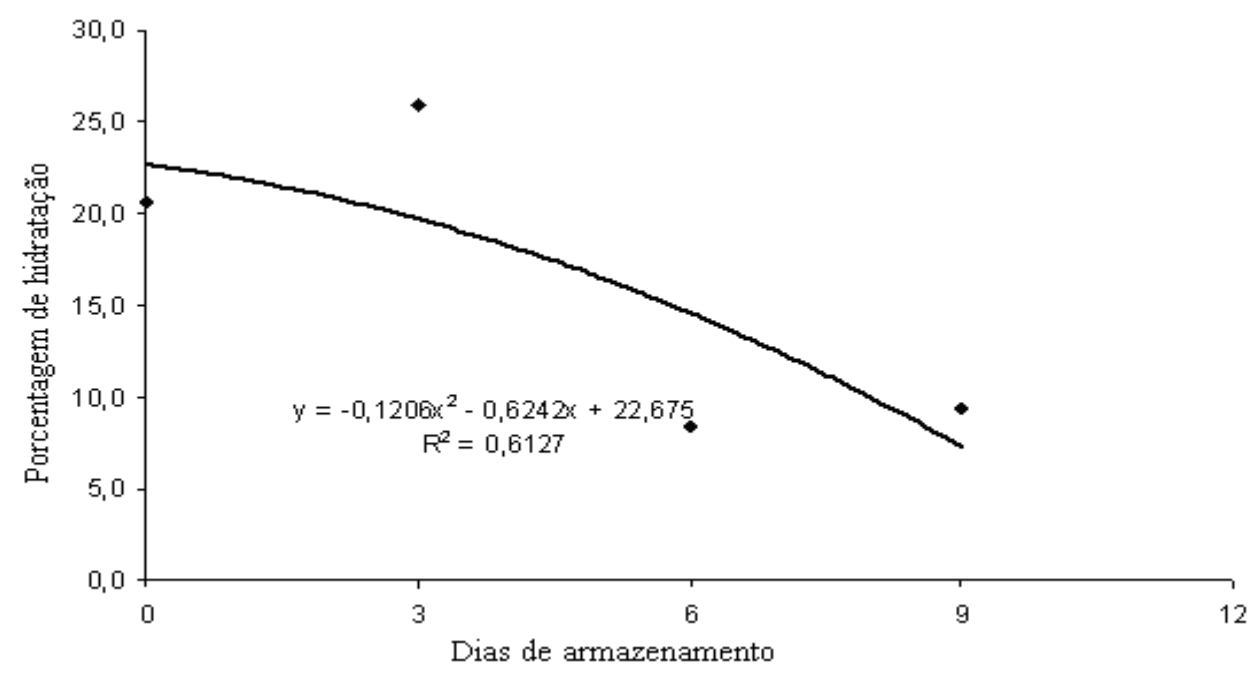


O ganho de peso médio durante a cocção das raízes de mandioca varia com a temperatura, cultivares e idade das raízes (BUTARELO et al., 2004). Eggleston e Asiedu (1994) encontraram valores de hidratação que variaram entre $0,04 \mathrm{e}$ $11,52 \%$ para oito variedades de mandiocas, colhidas 16 meses após o plantio, mas o tempo de cocção foi igual para todas as amostras e fixado em $20 \mathrm{~min}$.

Visualmente, pôde-se detectar a deterioração fisiológica com o escurecimento vascular das MMP. O aparecimento de manchas de cor rosa e enegrecido foi constatado a partir do dia $6^{\circ}$ dia de avaliação nos tratamentos "bandejas" e $9^{\circ}$ dia no tratamento "controle com vácuo". Alves et al. (2005) também fizeram esta constatação nestas embalagens e mencionam que a alteração possivelmente está correlacionada com a deterioração microbiológica causadas pela presença de fungos dos gêneros Fusarium e Penicillium. Bezerra et al. (2002) mencionam que estes são considerados os microorganismos mais importantes causadores de tal deterioração, a partir do $6^{\circ}$ dia de armazenamento. Guimarães et al. (2002) também verificaram que aos $6^{\circ}$ e $8^{\circ}$ dias, as mandiocas apresentaram um escurecimento de 15 a $25 \%$, respectivamente.

Alves et al. (2005) citam que as amostras armazenadas em bandeja de isopor envolta em filme de policloreto de vinila e embalagem multicamada seladas a vácuo apresentaram deteriorações fisiológicas, microbiológicas e sensoriais a partir do $7^{\circ}$ e $24^{\circ}$ dias de armazenamento, respectivamente.

Pedroso (2005) cita que as doses de 1 kGy e $3 \mathrm{kGy}$ foram as que melhores resultados apresentaram com relação as características físicoquímicas das MMP por um período de até 50 dias de armazenamento em refrigeração. As características sensoriais das mandiocas irradiadas com doses de 1 , 3, e $5 \mathrm{kGy}$ apresentaram melhores resultados no $21^{\circ}$ dia. $\mathrm{O}$ autor utilizou mandiocas industrializadas embaladas em sacos de polietileno a vácuo e realizou a irradiação nas doses de 0 (controle), 1,3 e
$5 \mathrm{kGy}$, sendo o armazenamento em temperaturas de refrigeração por 1, 21,30 e 50 dias, com o objetivo de avaliar o efeito sinergístico da embalagem a vácuo, da irradiação e da refrigeração na conservação de mandioca minimamente processada. Este autor encontrou um período de conservação superior aos pesquisadores citados na presente pesquisa. Para as MMP em bandejas recobertas com filme plástico, mesmo para dose $1,0 \mathrm{kGy}$, que foi umas das doses utilizadas, o resultado não foi superior em relação aos demais tratamentos. O tratamento a vácuo associado a refrigeração foi o procedimento adotado que permitiram um leve superioridade em relação aos demais tratamentos.

\section{Conclusões}

Nas condições em que foi realizada a pesquisa não foi observada diferença estatística entre as MMP dos diferentes tratamentos para a os parâmetros avaliados, exceto acidez total titulável e pH. A durabilidade das raízes foi de aproximadamente 6 dias. As avaliações seguiram apenas até o $9^{\circ}$ dia de armazenamento, pois após este período as raízes já apresentavam alterações fisiológicas e microbiológicas detectadas visualmente. As mandiocas minimamente processadas embaladas a vácuo apresentaram superioridade em relação aos demais tratamentos quanto aos valores de acidez, que foram inferiores, e ao aspecto visual das raízes.

\section{Referências}

ABREU, C. M. P.; SANTOS, C. D.; COSTA, L. Efeito da embalagem de polietileno e da refrigeração no escurecimento interno e na atividade de peroxidase e polifenoloxidase, durante a maturação de abacaxi. (Ananas comosus (L) Mess cv. Smooth Cayenne). Ciência e Tecnologia, Brasil, v. 22, n. 4, p. 454-465, 1998.

ALVES, A.; CANSIAN, R. L.; STUART, G.; VALDUGA, E. Alterações na qualidade de raízes de mandioca (Manihot esculenta Crantz) minimamente processadas. Ciência e Agrotecnologia, Lavras, v. 29, n. 2, p. 330-337, mar./abr. 2005. 
ASSUNÇÃO, C. A. G.; MATSUBARA, D.; GARCIA, S.; BELEIA, A. Microbiota deteriorante de mandioca minimamente processada e alternativas de controle. In: CONGRESSO BRASILEIRO DE CIÊNCIA E TECNOLOGIA DE ALIMENTOS, 18., 2002, Porto Alegre, RS. Anais... Porto Alegre: [s.n.], 2002. CDROM.

BASSI, D.; SELLI, R. Evaluation of fruit quality in peach and apricot. Adv Horticultural Sciense, Firenze, v. 4, n. 3, p. 107-112, 1990.

BEZERRA, V. S.; PEREORA, R. G. F. A.; CARVALHO, V. D. de; VILELA, E. R. Raízes de mandioca minimamente processadas: efeito do branqueamento na qualidade e conservação. Ciência e Agrotecnologia, Lavras, v. 26, n. 3, p. 564-575, maio/jul. 2002.

BURTON, W. G. Post-harvest physiology of food crops. London: Longman, 1982.

BUTARELO, S. S.; BELEIA, A.; FONSECA, I. C. de B.; ITO, K. C. Hidratação de tecidos de raízes de mandioca (Manihot esculenta Crantz.). Ciência e Tecnologia de Alimentos, Campinas, v. 24, n. 3, p. 311-315, jul./set. 2004.

CANO, M. P.; ANCOS, B. de; MANTALLANA, M. C.; CÁMARA, M.; REGLERO, G.; TABEA, J. Differences among spanish and Latin-American banana cultivars: morphological, chemical and sensory characteristics. Food Chemistry, London, v. 59, n. 3, p. 411-419, 1997.

CARVALHO, V. D. de; CHALFOUN, S. M.; JUSTE JÚNIOR, E. S. G. Métodos de armazenamento na conservação de raízes de mandioca: I. efeito da embalagem de polietileno e serragem úmida associada a tratamentos químicos na deterioração pós-colheita e qualidade das raízes. Revista Brasileira de Mandioca, Cruz das Almas, v. 4, n. 1, p. 79-85, 1985.

CEREDA, M. P.; SARMENTO, S. B. S.; WOSIACKI, G.; ABBUD, N. S. A mandioca (Manihot esculenta, C.) cultivar IAPAR-19 Pioneira 3- Características culinárias. Arquivos de Biologia e Tecnologia, Curitiba, v. 33, n. 3, p. 511-525, 1990.

COELHO, A. H. R. Efeito da idade de colheita sobre o grau de deterioração fisiológica e composição química das raizes de três cultivares de mandioca (Manihot es-culenta Crantz). 1992. Dissertação (Mestrado em Ciência dos Alimentos) - Universidade Federal de Lavras, Lavras.

COSTA NETO, P. R.; SPOTO, M. H. F.; DOMARCO, R. E. Uso da radiação gama a inibição do escurecimento da mandioca in natura, sem casca. Boletim de Centro de Pesquisa e Processamento de Alimentos, Curitiba, v. 15, n. 1, p. $75-83,1997$.
COSETENG, M. Y.; LEE, C. Y. Changes in apple polyphenoloxidase and polyphenol concentrations in relation to degree of browning. Journal of Food Science, Chicago, v. 52, n. 4, p. 985-989, 1987.

DIXON, R. A.; PAIVA, N. L. Stress-Induced phenylpropanoid metabolism. The Plant Cell, Rockville, v. 7, n. 7, p. 1085-1097, 1995.

DYER, W. E.; HENSTRAND, J. M.; HANDA, A. K.; HERRMANN, K. M. Wound induces the first enzyme of the shikimate pathway in Solanaceae. Procedures of National Academic Science, USA, v. 84, n. 2, p. 52025206, 1989.

EGGLESTON, G.; ASIEDU, R. Effects of boiling on the texture of cassava clones: a comparison of compressivestrength, intercellular adhesion and physicochemical composition of the tuberous roots. Tropical Science, London, v. 34, n. 3, p. 259-273, 1994.

GEORGE, J. B.; BROWNE, C. B. Changes in quality of fresh cassava tubers during storage. Tropical Science, London, v. 34, n. 2, p. 161-165, 1994.

GUIMARÃES, H. M. A.; ABREU, A. de S.; BATISTA, D.; INÁCIO, S. F.; ALCANFOR, F. M.; MENDES, S. dos S. Deterioração pós-colheita da mandioca (Maninhot esculenta Crantz.) mansa da cultivar cacau. In: CONGRESSO BRASILEIRO DE CIÊNCIA E TECNOLOGIA DE ALIMENTOS, 18., 2002, Porto Alegre, RS. Anais... Porto Alegre: [s.n.], 2002. CD-ROM.

KADER, A. A. Potential application of ionizing radiation in postharvest handling of fresh fruit and vegetables. Food Technology, Chicago, v. 40, n. 6, p. 117-121, 1986.

KATO, M. do S. A.; SOUZA, S. M. C. Conservação de raízes após colheita. Informe Agropecuário, Belo Horizonte, v. 13, n. 145, p. 9-14, 1987.

MONTALDO, A. Vascular streaking of cassava root tubers. Tropical Science, London, v. 15, n. 1, p. 39-46, 1973.

MORETTI, C. L. Manual de processamento mínimo de frutas e hortaliças. Brasília: EBRAE/EMBRAPA, 2007. $531 \mathrm{p}$.

OLIVEIRA, M. A.; PANTAROTO, S.; CEREDA, M. P. Efeito da sanitização e de agente antioxidante em raízes de mandioca minimamente processadas. Brazilian Journal of Food Technology, Campinas, v. 6, n. 2, p. 339344, 2003.

OUDIT, D. D. Polyethylene bags keep cassaca tubers fresh for several weeks at ambient temperatures. Journal of the Agricultural Society of Trinidad an Tobago, Centeno, v. 76, n. 1, p. 63-66, 1976. 
PEDROSO, B. M. Avaliação do efeito sinergístico da embalagem a vácuo, irradiação e refrigeração da mandioca minimamente processada. 2005. Dissertação (Mestrado em Ciências de Tecnologia NuclearAplicações) - Instituto de Pesquisas Energéticas e Nucleares, São Paulo.

PEREIRA, A. S.; LORENZI, J. O.; VALLE, T. L. Avaliação do tempo de cozimento e padrão de massa cozida em mandioca de mesa. Revista Brasileira de Mandioca, Cruz das Almas, v. 4, n. 1, p. 27-32, jun. 1985.

PINELI, L .L. O. Caracterização fisica, química , sensorial e nutricional de batatas minimamente processadas. 2005. Dissertação (Mestrado em Nutrição Humana) - Universidade de Brasília. Faculdade de Ciências da Saúde. Programa de Pós-graduação em Nutrição Humana, Brasília.

QUEVEDO, M. A.; DATA, E. S.; MATURAN, E. Storage of cassava roots in polyethylene bags. Radix, Philippines, v. 8, n. 2, p. 7-10, 1986.

SANTIN, M. La irradiación de los alimentos. Zaragoza: Acríbia, 2000.

SILVA, V. V.; SOARES, N. F. F.; GERALDINI, R. M. Efeito da embalagem e temperatura de estocagem na conservação de mandioca minimamente processada. Brazilian Journal of Food Technology, Campinas, v. 6, n. 2, p. 197-202, 2003.
TAPE, N. W. Protegendo nossas colheitas. [s.1]: International Consultative Group on Food Irradiation, 1996.

URBAIN, W. M. Food irradiation. Orlando: Academic Press, 1986.

VESCOVO, M.; TORRIANI, S.; ORSI, C.; MACCHIAROLO, F.; SCOLARI, G. Application of antimicrobial: producing lactic acid bacteria to control pathogens in ready-to-use vegetables. Journal Applied Bacteriology, Oxford, v. 81, n. 2, p. 113-119, 1996.

VIEITES, R. L.; EVANGELISTA, R. M.; SILVA, A. P. Radiação gama no melão minimamente processado. In: CONGRESSO BRASILEIRO DE CIÊNCIA E TECNOLOGIA DE ALIMENTOS, 17., 2000, Fortaleza. Anais... Fortaleza: SBCTA, 2000. CD-ROM.

VIEITES, R. L.; EVANGELISTA, R. M.; CAMPOS, A. J. de; MOREIRA, G. C. Efeito da embalagem e da irradiação gama no controle da contaminação microbiana da manga minimamente processada. Semina: Ciências Agrárias, Londrina, v. 25, n. 3, p. 197-206, jul./set. 2004.

WILEY, R. C. Frutas y hortalizas minimamente processadas y refrigeradas. Zaragoza: Acríbia, 1997.

. Minimally processed refrigerated fruits and vegetables. New York: Chapman \& Hall, 1994. 368 p. 